\title{
Platelet and red blood cell interactions and their role in rheumatoid arthritis
}

\author{
Oore-ofe O. Olumuyiwa-Akeredolu ${ }^{1}$ and Etheresia Pretorius ${ }^{1 *}$
}

\begin{abstract}
Cytokines, lymphocytes, platelets and several biomolecules have long been implicated in the pathology of rheumatoid arthritis (RA), and the influences of antibody production and tagging, and cytokine, chemokine and enzyme production at specific rheumatoid joints were thought to be exclusive to the advancement of disease parameters. Another role player in RA is red blood cells (RBCs) which, of late, have been found to be involved in RA pathobiology, as there is a positive correlation between RBC counts and joint pathology, as well as with inflammatory biomarkers in the disease. There is also an association between RBC distribution width and the incidence of myocardial infarction amongst RA patients, and there is a change in the lipid distribution within RBC membranes. Of late, certain RBC-associated factors with previously obscure roles and cell-derived particles thought to be inconsequential to the other constituents of plasma were found to be active biomolecular players. Several of these have been discovered to be present in or originating from RBCs. Their influences have been shown to involve in membrane dynamics that cause structural and functional changes in both platelets and RBCs. RBC-derived microparticles are emerging entities found to play direct roles in immunomodulation via interactions with other plasma cells. These correlations highlight the direct influences of RBCs on exacerbating RA pathology. This review will attempt to shed more light on how RBCs, in the true inflammatory
\end{abstract}

*Etheresia Pretorius

resia.pretorius@up.ac.za

1 Department of Physiology, Faculty of Health Sciences, University of Pretoria, Private Bag x323, Arcadia 0007, South Africa milieu of RA, are playing an even greater role than previously assumed.

Keywords Rheumatoid arthritis $\cdot$ Red blood cell · Platelet $\cdot$ Microparticles $\cdot$ Inflammation $\cdot$ Membrane

\section{Introduction}

Rheumatoid arthritis (RA) is a chronic systemic disease affecting joints, connective tissues, muscles, tendons and fibrous tissue. It is typically associated with some degree of immobility, persistent synovitis, inflammation and generation of autoantibodies and can be disabling and sometimes disfiguring [1]. The disease prevalence varies between 0.3 and $1 \%$, and despite advances in treatment over past few decades, as a result of its comorbidities, the life expectancy of patients is reduced by 3-10 years [2]. The risk factors can be classified into non-modifiable, such as genetic or gender-based categories, and modifiable, such as environmental or lifestyle-based categories. The majority of RA falls into those caused by genetic factors, while environmental factors add cumulatively to the risk of developing the disease $[3,4]$.

The pathophysiology of RA is complex, perpetuated by an arsenal of cells whose functions have been altered often by RA-associated genes and/or environmental triggers and converted to autoimmune cells and complexes, or made to follow an inflammatory pathway [5, 6]. Prominent amongst the cytokine mediators of inflammation triggered by lymphocytic activities are tumour necrosis factor (TNF- $\alpha$ ) and interleukins (IL-1, IL-6) [5], resulting in increasing levels of oxidative stress [7]. Lipid parameters (e.g. cholesterol levels) of sufferers are also distinctly altered and resistant to potential modification [8]. The inflammatory processes 
in turn alter the attributes and functions of platelets and red blood cells (RBCs), manifesting in the development of other progressive features of the disease $[9,10]$. Research has already established that there is a positive relationship existing between platelet and RBC counts and the levels of erosion occurring in RA joints [11]. However, the capacity of inflammation to transform RBC into pathogenic cells has not fully been explored in RA.

Therefore, in the current manuscript, we performed a comprehensive search on MEDLINE, Google Scholar, Scopus and Web of Science, following the guidelines stipulated by Gasparyan and coworkers in 2011 [12]. We performed our search for the literature using keywords specific to the red blood cell (RBC) in rheumatoid arthritis, and the keywords were: erythrocyte rheumatoid arthritis, erythrocyte autoimmunity, erythrocyte platelet interaction, erythrocyte membrane, erythrocyte protein, erythrocyte microparticle, erythrocyte inflammation, lysophosphatidic acid. Figure 1 shows a layout of the current manuscript.

\section{RBC pathology in relation to $R A$ pathology}

A prominent measure recommended by the American College of Rheumatology and utilized by rheumatologists through which disease activity may be monitored is the erythrocyte sedimentation rate (ESR), and this is affected by changes in the indices of blood cells, especially those of RBCs [13]. The ESR for RA patients is increased, as the inflammatory state causes platelets to be in a hyperstimulated state and induces clustering of immune cells and proteins, which have been shown to be markers of the disease process [14]. The predisposition to clotting is as a result of inflammation which increases the presence and activity of clotting factors [15]. A recent study demonstrated how raised levels of this marker directly correlated with the risk for heart failure in patients [16]. Properties like RBC size and the blood $\mathrm{pH}$ also affect the ESR, and these may be altered in the disease.

The inflammatory milieu in rheumatoid arthritis has been shown to affect RBCs $[10,17,18]$. Anaemia, a comorbidity in RA, is a result of increased eryptosis of bone marrow erythroid cells [19]. It has a prevalence of about $30 \%$ and was found to be more frequently associated with chronic conditions [20]. In early stages, it is caused by IL- 6 suppression of erythropoiesis in bone marrow, but this type does not contribute to mortality [21]. The direct cause of anaemia in chronic RA has therefore frequently been attributed to the same factors that propagate disease parameters.

In addition to effects that RA pathology causes to RBCs, evidence suggests that they are equally potent in their capacity to aggravate inflammation in situations where

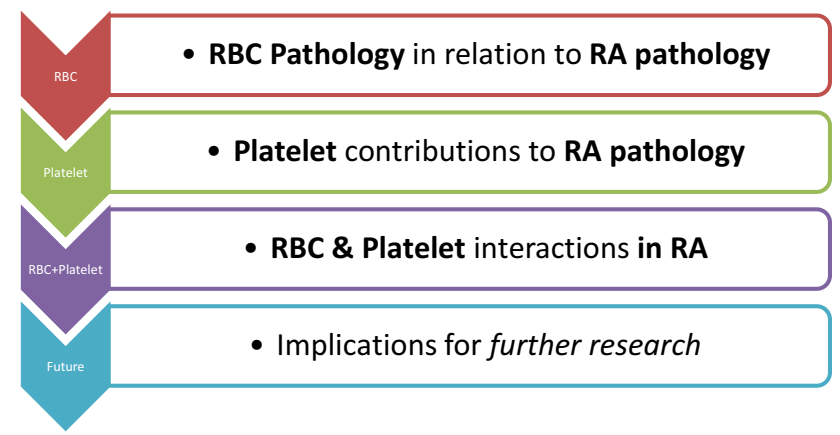

Fig. 1 Layout of manuscript-summary of underscored roles of red blood cells (RBCs) within rheumatoid arthritis (RA)

platelet influences were thought to dominate. Their numbers have been found to be directly correlated with degrees of cartilage erosion occurring in the rheumatoid synovium [11], and there seems to be a direct link between the presence of these cells and inflammatory biomarkers in RA [22] and also on raising the risk for myocardial infarction amongst patients [23].

RBCs maintain characteristic structures with the help of a phospholipid bilayer and several transmembrane proteins. Proteins, functioning as receptors or transporters, are responsible for the elastic and structural properties of RBCs, as well as their interactions with the biochemical milieu [24]. Some of these proteins such as calpastatin have the potential to stimulate inflammatory activities in other cells or become antigens in the autoimmune atmosphere of the RA patient's physiology $[25,26]$.

The protein content in the rheumatoid circulation is staggering. The disease is characterized by predominance of acute-phase response proteins such as fibrinogen, amyloid proteins and the globulins over albumin [27]. RBCs in these patients have been shown to be affected by the presence of excessive amounts of proteins circulating in the blood, as well as the levels of generated free radicals [28]. Levels of these proteins have been found to be the most significant indicators of radiographic progression [29]. An integrinassociated protein CD47 was also found to be a mediator for fibrinogen interactions with RBC membranes [30]. Recent studies have unveiled the potential for high-concentration fibrinogen to affect membrane deformability and regulation of free radicals in the presence of acetylcholine [31, 32]. The adsorption of these proteins into RBC membranes within the RA circulation is also a possibility that cannot be ruled out [33]. Furthermore, adsorption of charged proteins has also been shown to affect the distribution of lipids within membranes [34]. The structure and interactions of RBCs may consequently be hampered by the transmembrane protein changes, a possible cause for the characteristic phenomenon of high sedimentation rates in plasma. 
The oxidative state of RBC membrane proteins in rheumatoid circulation is altered, resulting in the severe state of oxidative stress in RA [35]. Free radicals such as nitric oxide have been found to bind and exacerbate the oxidative states of RBCs [36]. Furthermore, an RBC carries an overall negative charge, which should enable it offset the influence of pro-inflammatory factors, but this charge is altered by raised levels of oxidative stress [35]. Ergothioneine, an active transporter of cations on the RBC membrane is found at significantly higher levels in RA patients compared to patients with other chronic inflammatory diseases [18]. On the other hand, protective glutathione reductase, normally produced by RBCs, is insufficient to cancel out effects of the toxic oxygen metabolites, resulting in lipid peroxidation [37]. Glyceraldehyde-3-phosphate dehydrogenase (GAPDH), a critical metabolic enzyme affiliated with the membrane undergoes ADP ribosylation and is inhibited from participation in its multiple roles within the cell cycle [38]. With overwhelming oxidation of proteins responsible for reversing these effects, the cell cycle suffers and eryptotic pathways eventually ensue.

The lipid parameters of RBC membranes have also been shown to influence their inflammatory state and participation in thrombotic pathologies, and this is critical to RA plasma characterized by dyslipidaemia [39]. Lipids are particularly influential in modulating the levels of inflammation occurring in the disease and determining the occurrence of comorbidities [40]. It was revealed that the lipid distribution in RA plasma and RBC bilayers is altered, showing a decreased level of cholesterol and phospholipids when compared to healthy controls [17]. Studies have shown that the amounts of cholesterol incorporated into the cell's phospholipid bilayer can determine its capacity to express phosphatidylserine (PS) on the outer leaflet independent of ATP-driven flippases [41]. This supports the possibility that portions of the membrane are budding off to form microparticles (MPs). They have been described in several inflammatory diseases and could be involved in RA pathobiology [42]. Investigation of the proteome of these RBC-derived microparticles (RMPs) provides evidence that they occasionally carry the crucial band 3 protein, which increases the chances that they may also express Rh-associated CD47 and present fibrinogen as an antigen [43, 44]. Expression of PS on cell membranes has also been shown to play a role in influencing the electrostatic association of cationic ligands with the cell [45]. With the reduced quantities of cholesterol in RA RBCs, they are likely to show greater degrees of membrane pathology.

Lysophosphatidic acid (LPA), a recently described lipidderived potentiator of synovial events originating from platelets, has been described in RA [46]. Emerging studies of signalling pathways suggest that its production is triggered when phospholipase A2 (PLA2) hydrolyses and causes exposure of PS [47, 48]. This leads to the opening of calcium $\left(\mathrm{Ca}^{2+}\right)$ channels in the membrane, which activates calpain/calpastatin pathways and ends in vesiculation $[49,50]$. This directly affects the deformability and aggregatory properties of the cells [51]. LPA has also been found capable of inducing RMP generation [52]. The composition of lipids and proteins of the RMPs is varied and affected by the membrane domains of the originating cell, which in turn determines its stimulatory signal on the target cell [53, 54]. The expression of PS by RBC membranes could also indicate disengagement in the some lipid associations critical to the maintenance of structure by underlying spectrin proteins, resulting in changes in membrane ultrastructure [55].

Beyond the influence of inflammatory stress on these cells, RBCs also contribute directly to RA pathology through immunoregulation. They have been shown capable of regulating cell cycles of the CD4+ and CD8+ T cell population and releasing factors that promote their growth and survival [56-58]. RMPs were also recently implicated in immune cell activation in addition to initiating thrombin generation [59]. Lipid rafts and their constituents are also critical to determining constituent membrane proteins and therefore affect intercellular biochemical signalling. There is proof within the literature that $\mathrm{T}$ cell antigen receptors are influenced by similar modifications [60]. Taking into account what the literature says, and considering the substantial role $\mathrm{T}$ cell signalling contributes to the pathophysiology of the disease, we suggest that some signalling between RBC membranes and T cells might therefore have been taking place undetected. The participation of these cells in immune activities requires further study in RA. A proposed pathway to RBC membrane pathology and direct involvement in RA is described in Fig. 2.

The influences of platelet MPs on immunity have been well investigated in the disease, and those from RBCs might therefore also play an important role in the disease. Considering the degree of lipid dysregulation occurring within RBC membranes, it is likely that many more undiscovered pathways are aggravating the autoimmune milieu. Figure 3 is a depiction of the implied interrelationships between RBCs and RA pathology.

\section{Platelet contributions to RA pathology}

The inflammatory milieu of rheumatoid plasma provides sufficient agonistic stimuli for platelets in RA. Their numbers and degree of activity have been found to be significantly amplified in the disease [9]. Thrombocytosis was found in a large proportion of RA patients, attributed mostly to their reduced survival and increased turnover rates [61]. Platelet numbers have been directly correlated with clinical and 


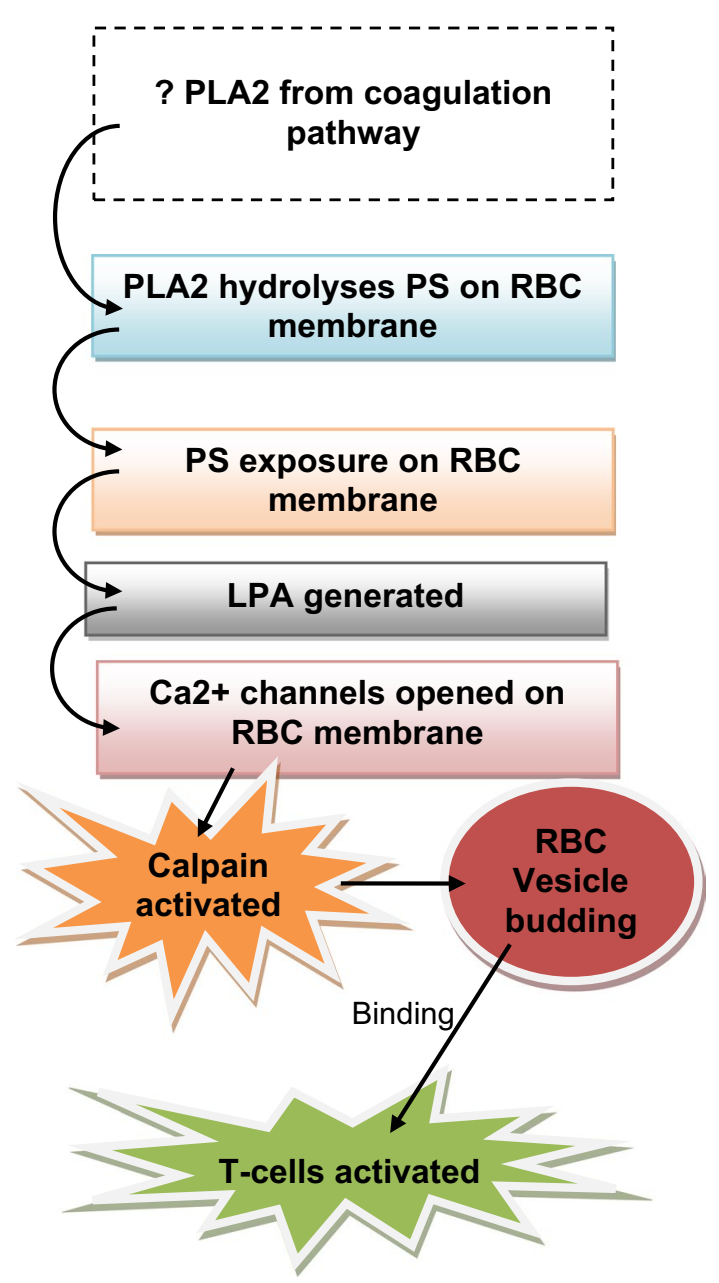

Fig. 2 Proposed inter- and intracellular pathophysiology connecting RA RBCs to T cell activation

other investigative measures of disease activity such as ESR, C-reactive protein, rheumatoid factor, levels of leucocyte and acute-phase proteins but inversely associated with albumin and haemoglobin levels [62]. Their volumes have also been markedly correlated with disease activity [63]. Increased platelet volumes were found to be directly affiliated with the risk of cardiac complications and hypertension [9, 64]. This links them directly to the comorbidity risk of RA.

Platelets have the capacity to function as delivery vehicles for a plethora of chemokines, cytokines, growth factors, autocrine and paracrine moieties which may or may not be present in the surrounding serum, and their activation sustains autoimmune pathways [65, 66]. They are also capable of post-translational automodification of their mRNAs following release from megakaryocytes via activation by molecular signals common to oxidative or haemostatic pathways [67]. They enhance vascular permeability and release MPs, which have been implicated in aiding the formation of immune complexes via autoantigen expression $[68,69]$. MPs were also found to be carriers of the C-type lectin-like receptor 2 (CLEC-2) as with the originating cells which enables cleavage of the platelet glycoprotein GPVI [70]. Whether this is required prior to activation via collagen binding is yet to be established. Their mitochondria are capable of promoting oxidative stress and increasing pathophysiologic functions in the cell [71].

Platelet function in peripheral circulation has also been found to be different from its activity in the RA synovium. Hyperactive platelets and their products are found in higher proportions at inflammatory sites than in circulation [72]. While inflammatory pathways differ from haemostatic, they share several common mediators that may cause platelet functions to overlap [73]. Disease features like invasion of synovial membranes and angiogenesis indicate platelet participation [74]. Differential binding and functions of the platelet receptors within circulation are different from their functions in the rheumatoid synovium, causing corresponding variations in its degrees of activity within circulation of RA patients.

\section{RBC and platelet interactions in RA}

Platelet interactions with RBCs are likely events that happen frequently within macro- and microvasculature. Hence,
Fig. 3 Possible RBC and RA pathology interconnectedness

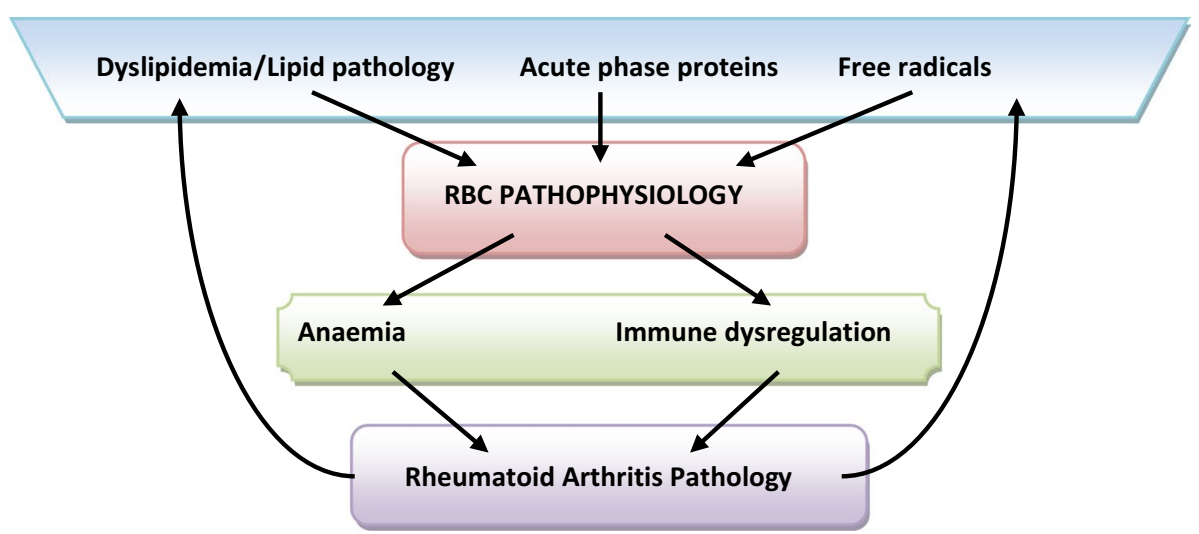


understanding their biochemical and biomolecular associations is important to detect potential implications to RA pathophysiology. Far beyond the placid role allotted to these cells within circulation, their associations are proving to be critical to the disease parameters. The magnitude of RBC and platelet influences on pathology can be observed just based on their proximity within circulation. The $\alpha \operatorname{IIb} \beta 3$ platelet integrin proteins (GPIIbIIIa) are central to coagulation and fibrinogenesis and platelet interactions. However, following activation via collagen binding, these receptor's responses were found to be significantly enhanced by prothrombotic releasates from a suspension containing both platelets and RBCs [75]. The releasates contained greater amounts of ADP, ATP and thromboxane B2 (TX B2) than those derived from platelets acting alone [76]. These RBCinduced responses were found to be sustained even after the removal of the initial agonist trigger and following inhibition of TX synthesis.

It has been established that majority of the cell-derived microparticles occurring within circulation and a few occurring within the synovial space, as described by investigators, originate from RBCs [77, 78]. These RMPs effected expansion of the $\mathrm{T}$ lymphocyte pool via antigen presentation. Some of those investigated were found to be carriers of complement proteins or tissue factors and were less sensitive to clearance by annexin V [79]. There is further evidence that they serve as vectors and modify activities within target cells [80].

Interactions of these particles with platelets have also triggered thrombotic signalling [77, 81]. Assays of thrombin production were able to confirm that RBCs and their products were capable of independent thrombin generation, once stimulated $[82,83]$. Several studies of other diseases confirm this role of consistent contribution to hypercoagulability by RBCs [84-86]. RBC MPs are also capable of inducing platelet hyperstimulation following collagen activation [76]. These RMPs were found capable of inducing ex vivo platelet-platelet aggregates [87] and sometimes express PS on their surface which enables platelet binding and activation and in turn modifies the chemokine ligands they carry [88]. With angiogenesis at inflamed joints being a direct consequence of disease progression, these cells gain direct access to each other's molecular and biochemical influences so there is likely exponentiation of stimulation. This could possibly be a mechanism through which adjacent RBCs elevate the inflammatory responses of the platelets within rheumatoid serum, in which variable volumes of degraded collagen are present [89]. Figure 4 depicts some of the physiological relationships described.

Similarities between the morphological characteristics of cells undergoing membrane dysregulation to those following eryptotic pathways suggest they share common biochemical players [90]. An example of this is thromboxane,
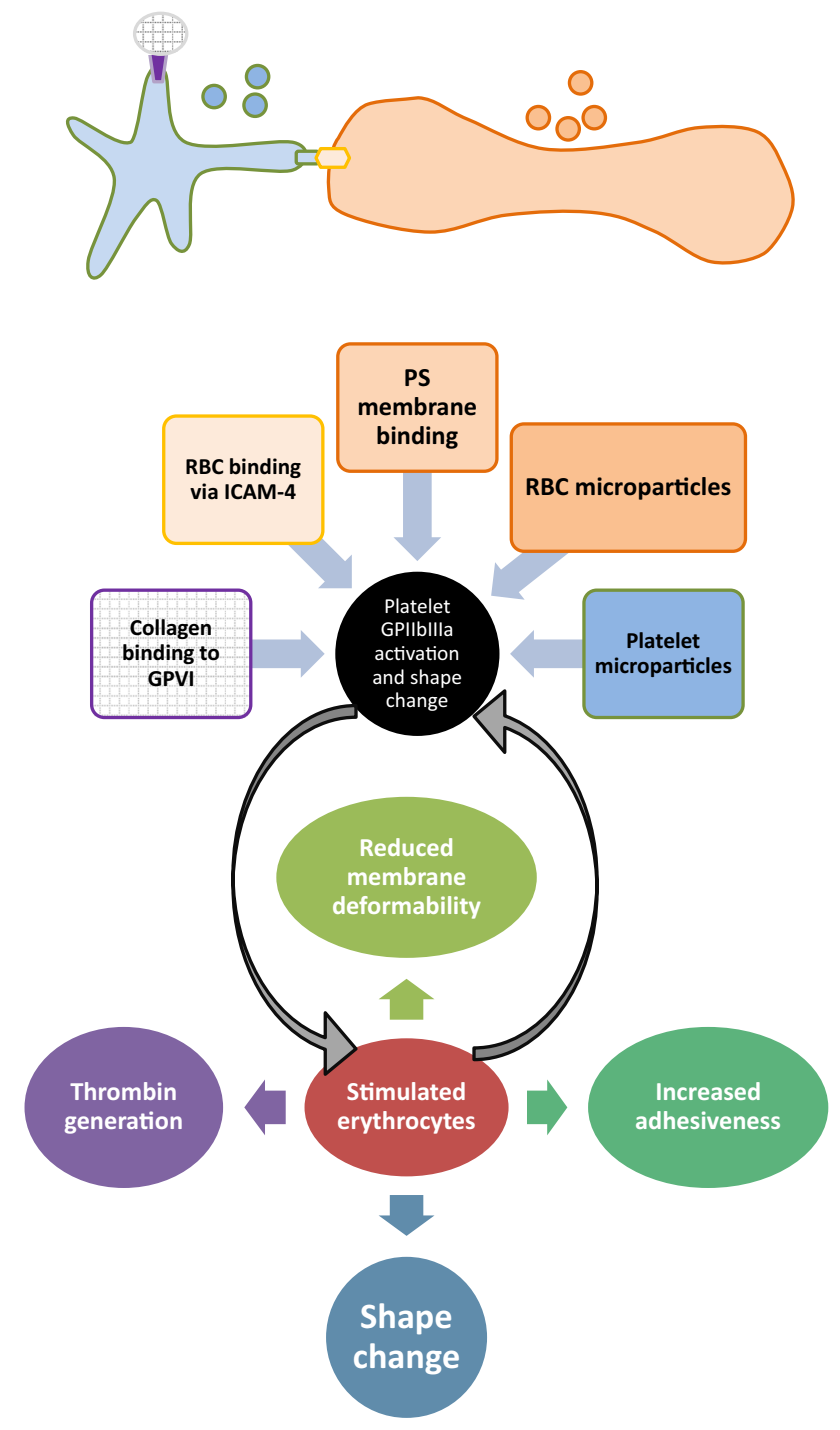

Fig. 4 Pathophysiological implications of RBC-platelet interactions in RA circulation

which was found to stimulate RBCs by inducing PS exposure on their surfaces, followed by an increase in cytosolic calcium content [76]. These responses have been found to be associated with reduced membrane deformability, increased adhesion, formation of pathomorphologies and a precursor to eryptosis [91-93]. The PS exposure further increases the adherence of RBCs to platelets and induces thrombosis [93]. It is hence likely that structural variants and adhesive associations observable within the RA RBC pool could also be a result of this interaction-based effect.

Some adhesion proteins have been identified enabling direct contact between platelets and RBCs. Intercellular adhesion molecule 4 (ICAM-4 or CD242), a blood group antigen within the Landsteiner Wiener family of glycoproteins, was recently identified on RBC membranes enabling direct binding to the platelet's $\alpha \operatorname{IIb} \beta 3$ integrin $[94,95]$. Its 


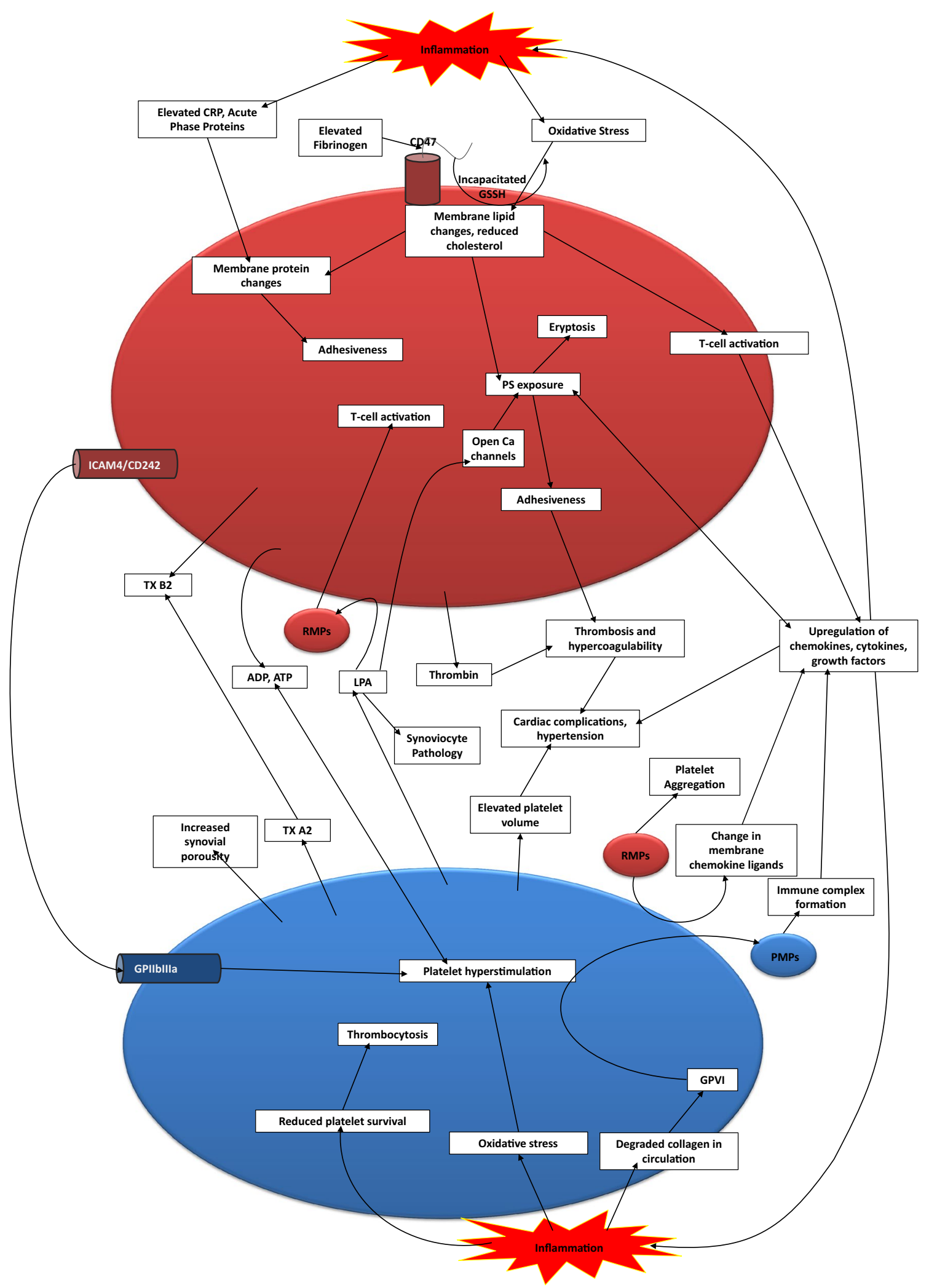

Fig. 5 Pathophysiological interrelationships existing between blood cells as described in this review. Red circles represent the RBC and its microparticles (RMPs), while the blue circles represent the plate- let and its microparticles (PMPs). The arrows indicate associations between biochemical, molecular, cellular and pathophysiological features of the disease 
adhesive potential to diverse other components of vasculature makes it a potential trigger of thrombotic and inflammatory pathways. This is likely a preceding step to platelet-enabled coagulation during thrombotic events while the residues are opsonised for phagocytosis during clot resolution. However, RBCs that have undergone eryptosis, especially due to glucose deprivation, have been found to bind platelet PS receptors and potentially reduce the solubility of the thrombus [93]. It is therefore possible that biophysical changes, adhesive associations and thrombotic events observable within RA vasculature could also be a result of this interaction-based effect.

The cumulative effect of RBC presence within the rheumatoid milieu is therefore important in understanding the disease. Studies of other chronic conditions have demonstrated that changes occur to the lipid and protein composition of its cell membrane which potentially contributes to disease course [96-98]. In RA, however, literature is sparse which demonstrate exclusive roles played by RBC-originating receptors, molecules and signalling pathways on the disease. A general overview of the relationships described in this manuscript is shown in Fig. 5.

\section{Conclusion and further research}

It is probable that as a result of ex vivo protocols utilized in separating and purifying protein systems for analyses of intracellular and molecular events and interactions, certain biochemical processes are missed in the discovery of pathophysiological pathways [99]. Pharmaceutical researchers targeting molecular markers of disease frequently encounter their influences during inquiries into unforeseen treatment outcomes. Aspirin resistance has already been established to be partly due to contributions from RBCs [100]. A combination of biochemical signals from the cellular players in the disease and the RBCs own propensity to contribute pathogenic stimuli may therefore be identified through investigations of progressive RA. Perhaps a closer look at the molecular and biochemical factors present within and around RBCs using conditions most identical to those in vivo would be a more productive way of improving therapeutic outcomes. Investigations of antigen systems being targeted by immune cells may also uncover associations with the RBC [26]. With the advent of utilizing platelets as delivery vehicles for therapeutic modulators of synovial diseases, RBCs with their diverse molecular and biochemical contributions should not be left out.

This review aims to emphasize an existing gap in knowledge with respect to RBCs in RA. Future studies should ascertain the following: Are there other contributions of RBCs to RA and are there currently limitations to the evaluation of the factors present within or being produced by
RBCs that make investigating their contributions to the disease onerous?

Existing studies frequently attribute MP origin to either platelets, monocytes or immune cells, but could there be other sources triggering their formation? Current literature is sparse with only one describing the proteome constitution of RBC-derived microparticles/microvesicles, and this is not in RA. Could further investigation discover the presence of other factors that may not originate from RBCs, platelets, plasma or immune cells? Which markers are specific for the identification of these vesicles and what procedures are likely to perform the most accurate analyses? If spectrin and other skeletal proteins are involved in the maintenance of membrane integrity, could they also be present in RA-derived RBC vesicles? What could this mean to the functionality of the RBC in RA? Are there differences in the composition of microparticles/microvesicles in different diseases and could their formation imply increased risk for other comorbidities? In summary, RBCs may not be directly culpable for RA pathogenesis, but they certainly are involved in advancing disease parameters, and their participation in the disease process should be explored further.

Conflict of interest The authors have no conflict of interest to declare.

\section{References}

1. Scott DL, Wolfe F, Huizinga TWJ (2010) Rheumatoid arthritis. Lancet 376(9746):1094-1108

2. Tobón GJ, Youinou P, Saraux A (2010) The environment, geoepidemiology, and autoimmune disease: rheumatoid arthritis. J Autoimmun 35(1):10-14

3. Scott IC, Seegobin SD, Steer S, Tan R, Forabosco P, Hinks A, Eyre S, Morgan AW, Wilson AG, Hocking LJ et al (2013) Predicting the risk of rheumatoid arthritis and its age of onset through modelling genetic risk variants with smoking. PLoS Genet 9(9):e1003808

4. Bergström U, Jacobsson L, Nilsson J-Å, Wirfält E, Turesson C (2013) Smoking, low formal level of education, alcohol consumption, and the risk of rheumatoid arthritis. Scand J Rheumatol 42(2): 123-130

5. Cooles FA, Isaacs JD (2011) Pathophysiology of rheumatoid arthritis. Curr Opin Rheumatol 23(3):233-240. doi:10.1097/ BOR.1090b1013e32834518a32834513

6. van Beers JJBC, Pruijn GJ (2010) The role of synovial citrullinated proteins in the pathophysiology of rheumatoid arthritis. Protein Deimination in Human Health and Disease, pp 41-68

7. Seven A, Güzel S, Aslan M, Hamuryudan V (2008) Lipid, protein, DNA oxidation and antioxidant status in rheumatoid arthritis. Clin Biochem 41(7):538-543

8. Charles-Schoeman C, Lee YY, Grijalva V, Amjadi S, FitzGerald J, Ranganath VK et al (2012) Cholesterol efflux by high density lipoproteins is impaired in patients with active rheumatoid arthritis. Ann Rheum Dis 71:1157-1162

9. Gasparyan AY, Stavropoulos-Kalinoglou A, Mikhailidis DP, Toms TE, Douglas KMJ, Kitas GD (2011) Platelet function in 
rheumatoid arthritis: arthritic and cardiovascular implications. Rheumatol Int 31:153-164

10. Luquita A, Uril L, Svetaz MJ, Gennaro AM, Volpintesta R, Palatnik S et al (2009) Erythrocyte aggregation in rheumatoid arthritis: cell and plasma factor's role. Clin Hemorheol Microcirc 41:49-56

11. Lu A (2009) Correlations among cartilage erosion, IgA level, red blood cell and platelet counts in 436 rheumatoid arthritis patients with path analysis. In: Bioinformatics and Biomedical Engineering, Beijing: ICBBE, pp 1-3

12. Gasparyan AY, Ayvazyan L, Blackmore H, Kitas GD (2011) Writing a narrative biomedical review: considerations for authors, peer reviewers, and editors. Rheumatol Int 31(11):1409-1417

13. Verma N, Misra R, Singh R, Agarwal S, Naik S (2002) Serological correlates of inflammation in rheumatoid arthritis: usefulness of acute phase reactants in monitoring disease activity. J Indian Rheumatol Assoc 10:1-4

14. Bunescu A, Seideman P, Lenkei R, Levin K, Egberg N (2004) Enhanced Fcgamma receptor I, alphaMbeta2 integrin receptor expression by monocytes and neutrophils in rheumatoid arthritis: interaction with platelets. J Rheumatol 31(12):2347-2355

15. Xu J, Lupu F, Esmon CT (2010) Inflammation, innate immunity and blood coagulation. Hamostaseologie 30(1):5-6, 8-9

16. Maradit-Kremers H, Nicola PJ, Crowson CS, Ballman KV, Jacobsen SJ, Roger VL, Gabriel SE (2007) Raised erythrocyte sedimentation rate signals heart failure in patients with rheumatoid arthritis. Ann Rheum Dis 66(1):76-80

17. Vijayakumar D, Suresh K, Manoharan S (2005) Altered pattern of lipids in plasma and erythrocyte membranes of rheumatoid arthritis patients. Indian J Clin Biochem 20(1):52-55

18. Taubert D, Lazar A, Grimberg G, Jung N, Rubbert A, Delank KS, Perniok A, Erdmann E, Schomig E (2006) Association of rheumatoid arthritis with ergothioneine levels in red blood cells: a case control study. J Rheumatol 33(11):2139-2145

19. Papadaki HA, Kritikos HD, Valatas V, Boumpas DT, Eliopoulos GD (2002) Anemia of chronic disease in rheumatoid arthritis is associated with increased apoptosis of bone marrow erythroid cells: improvement following anti-tumor necrosis factor- $\alpha$ antibody therapy. J Am Soc Hematol 100:474-482

20. Wilson A, Yu H, Goodnough LT, Nissenson AR (2004) Prevalence and outcomes of anemia in rheumatoid arthritis: a systematic review of the literature. Am J Med 116:50S-57S

21. Nikolaisen C, Figenschau Y, Nossent JC (2008) Anemia in early rheumatoid arthritis is associated with interleukin 6-mediated bone marrow suppression, but has no effect on disease course or mortality. J Rheumatol 35:380-386

22. Lee WS, Kim T-Y (2010) Relation between red blood cell distribution width and inflammatory biomarkers in rheumatoid arthritis. Arch Pathol Lab Med 134:505-506

23. Zhou Y, Zhang Q, Yan L, Li Y, Hua L (2015) Association between red cell distribution width and myocardial infarction in rheumatoid arthritis. Clin Chem Lab Med 53(7):e153-e155

24. Goodman SR, Daescu O, Kakhniashvili DG, Zivanic M (2013) The proteomics and interactomics of human erythrocytes. Exp Biol Med 238(5):509-518

25. Iwaki-Egawa $\mathrm{S}$, Matsuno $\mathrm{H}$, Yudoh $\mathrm{K}$, Nakazawa $\mathrm{F}$, Miyazaki $\mathrm{K}$, Ochiai A et al (2004) High diagnostic value of anticalpastatin autoantibodies in rheumatoid arthritis detected by ELISA using human erythrocyte calpastatin as antigen. J Rheumatol 31:17-22

26. Kontos S, Kourtis IC, Dane KY, Hubbell JA (2013) Engineering antigens for in situ erythrocyte binding induces T-cell deletion. Proc Natl Acad Sci 110(1):E60-E68

27. Meyer PWA, Hodkinson B, Ally M, Musenge E, Wadee AA, Fickl H, et al (2011) Circulating cytokine profiles and their relationships with autoantibodies, acute phase reactants, and disease activity in patients with rheumatoid arthritis. Mediators of inflammation 2010

28. Staroń A, Mąkosa G, Koter-Michalak M (2012) Oxidative stress in erythrocytes from patients with rheumatoid arthritis. Rheumatol Int 32(2):331-334

29. Wolfe F, Sharp JT (1998) Radiographic outcome of recent-onset rheumatoid arthritis: a 19-year study of radiographic progression. Arthritis Rheum 41(9):1571-1582

30. De Oliveira S, De Almeida VV, Calado A, Rosário HS, Saldanha C (2012) Integrin-associated protein (CD47) is a putative mediator for soluble fibrinogen interaction with human red blood cells membrane. Biochim Biophys Acta 1818(3):481-490

31. Saldanha C, Freitas T, Almeida JP (2012) Fibrinogen effects on erythrocyte nitric oxide mobilization in presence of acetylcholine. Life Sci 91(21-22):1017-1022

32. Saldanha C, Freitas T, Lopez de Almeida JP, Silva-Herdade A (2014) Signal transduction pathways in erythrocyte nitric oxide metabolism under high fibrinogen levels. Korea-Aust Rheol J 26(2):217-223

33. Glasmästar K, Larsson C, Höök F, Kasemo B (2002) Protein adsorption on supported phospholipid bilayers. J Colloid Interface Sci 246(1):40-47

34. Mbamala EC, Ben-Shaul A, May S (2005) Domain formation induced by the adsorption of charged proteins on mixed lipid membranes. Biophys J 88(3):1702-1714

35. Jewell SA, Petrov PG, Winlove CP (2013) The effect of oxidative stress on the membrane dipole potential of human red blood cells. Biochim Biophys Acta 1828(4):1250-1258

36. Hilliquin P, Borderie D, Hernvann A, Menkes CJ, Ekindjian OG (1997) Nitric oxide as s-nitrosoproteins in rheumatoid arthritis. Arthritis Rheum 40(8):1512-1517

37. Aryaeian N, Djalali M, Shahram F, Jazayeri S, Chamari M, Nazari S (2011) Beta-Carotene, Vitamin E, MDA, glutathione reductase and arylesterase activity levels in patients with active rheumatoid arthritis. Iranian J Public Health 40(2):102-109

38. Mohr S, Hallak H, de Boitte A, Lapetina EG, Brüne B (1999) Nitric oxide-induced S-glutathionylation and inactivation of glyceraldehyde-3-phosphate dehydrogenase. J Biol Chem 274(14):9427-9430

39. Toms TE, Symmons DP, Kitas DG (2010) Dyslipidaemia in rheumatoid arthritis: the role of inflammation, drugs, lifestyle and genetic factors. Curr Vasc Pharmacol 8:301-326

40. Myasoedova E, Crowson CS, Kremers HM, Roger VL, FitzGibbon PD, Therneau TM et al (2011) Lipid paradox in rheumatoid arthritis: the impact of serum lipid measures and systemic inflammation on the risk of cardiovascular disease. Ann Rheum Dis 70(3):482-487

41. van Zwieten R, Bochem AE, Hilarius PM, vanBruggen R, Bergkamp F, Hovingh GK, Verhoeven AJ (2012) The cholesterol content of the erythrocyte membrane is an important determinant of phosphatidylserine exposure. Biochim Biophys Acta 182(12):1493-1500

42. Rubin O, Canellini G, Delobel J, Lion N, Tissot J-D (2012) Red blood cell microparticles: clinical relevance. Transfus Med Hemother 39(5):342

43. Bosman GJ, Lasonder E, Groenen-Döpp YAM, Willekens FLA, Werre JM (2012) The proteome of erythrocyte-derived microparticles from plasma: new clues for erythrocyte aging and vesiculation. J Proteom 76:203-210

44. Mouro-Chanteloup I, Delaunay J, Gane P, Nicolas V, Johansen M, Brown EJ, Peters LL, Le Van Kim C, Cartron JP, Colin Y (2003) Evidence that the red cell skeleton protein 4.2 interacts with the Rh membrane complex member CD47 vol 101

45. Leventis PA, Grinstein S (2010) The distribution and function of phosphatidylserine in cellular membranes. Annu Rev Biophys 39:407-427 
46. Miyabe Y, Miyabe C, Iwai Y, Yokoyama W, Sekine C, Sugimoto K, Harigai M, Miyasaka M, Miyasaka N, Nanki T (2014) Activation of fibroblast-like synoviocytes derived from rheumatoid arthritis via lysophosphatidic acid-lysophosphatidic acid receptor 1 cascade. Arthritis Res Ther 16(5):461

47. Neidlinger NA, Larkin SK, Bhagat A, Victorino GP, Kuypers FA (2006) Hydrolysis of phosphatidylserine-exposing red blood cells by secretory phospholipase A2 generates lysophosphatidic acid and results in vascular dysfunction. J Biol Chem 281(2):775-781

48. Aoki J (2004) Mechanisms of lysophosphatidic acid production. In: Seminars in cell \& developmental biology: 2004. Elsevier, pp 477-489

49. Yang L, Andrews DA, Low PS (2000) Lysophosphatidic acid opens a $\mathrm{Ca}++$ channel in human erythrocytes. Blood 95(7):2420-2425

50. Khorchid A, Ikura M (2002) How calpain is activated by calcium. Nat Struct Mol Biol 9(4):239-241

51. Muravyov A, Tikhomirova I (2012) Role Ca2 + in mechanisms of the red blood cells microrheological changes. In: Calcium signaling. Springer, pp 1017-1038

52. Chung S-M, Bae O-N, Lim K-M, Noh J-Y, Lee M-Y, Jung Y-S, Chung J-H (2007) Lysophosphatidic acid induces thrombogenic activity through phosphatidylserine exposure and procoagulant microvesicle generation in human erythrocytes. Arterioscler Thromb Vasc Biol 27(2):414-421

53. Weerheim A, Kolb A, Sturk A, Nieuwland R (2002) Phospholipid composition of cell-derived microparticles determined by one-dimensional high-performance thin-layer chromatography. Anal Biochem 302(2):191-198

54. Butikofer P, Kuypers F, Xu C, Chiu D, Lubin B (1989) Enrichment of two glycosyl-phosphatidylinositol-anchored proteins, acetylcholinesterase and decay accelerating factor, in vesicles released from human red blood cells. Blood 74(5):1481-1485

55. An X, Guo X, Sum H, Morrow J, Gratzer W, Mohandas N (2004) Phosphatidylserine binding sites in erythroid spectrin: location and implications for membrane stability. Biochemistry 43(2):310-315

56. Arosa FA, Pereira CF, Fonseca AM (2004) Red blood cells as modulators of $\mathrm{T}$ cell growth and survival. Curr Pharm Des 10(2):191-201

57. Profumo E, Buttari B, Petrone L, Straface E, Gambardella L, Pietraforte D, Genuini I, Capoano R, Salvati B, Malorni W (2011) Redox imbalance of red blood cells impacts T lymphocyte homeostasis: implication in carotid atherosclerosis. Thromb Haemost 106(6):1117

58. Antunes RF, Brandão C, Maia M, Arosa FA (2011) Red blood cells release factors with growth and survival bioactivities for normal and leukemic T cells. Immunol Cell Biol 89(1):111-121

59. Rubin O, Delobel J, Prudent M, Lion N, Kohl K, Tucker EI, Tissot JD, Angelillo-Scherrer A (2013) Red blood cell-derived microparticles isolated from blood units initiate and propagate thrombin generation. Transfusion 53(8):1744-1754

60. Kabouridis PS, Jury EC (2008) Lipid rafts and T-lymphocyte function: implications for autoimmunity. FEBS Lett 582(27):3711-3718

61. Hutchinson RM, Davis P, Jayson MI (1976) Thrombocytosis in rheumatoid arthritis. Ann Rheum Dis 35(2):138-142

62. Farr MSD, Constable TJ, Hawker RJ, Hawkins CF, Stuart J (1983) Thrombocytosis of active rheumatoid disease. Ann Rheum Dis 42:545-549

63. Yazici S, Yazici M, Erer B, Erer B, Calik Y, Ozhan H et al (2010) The platelet indices in patients with rheumatoid arthritis: mean platelet volume reflects disease activity. Platelets 21:122-125
64. Gasparyan AY, Stavropoulos-Kalinoglou A, Toms TE, Douglas KMJ, Kitas GD (2010) Association of mean platelet volume with hypertension in rheumatoid arthritis. Inflamm Allergy Drug Targets 9:45-50

65. Habets KL, Huizinga TW, Toes RE (2013) Platelets and autoimmunity. Eur J Clin Invest 43:746-757

66. Boilard E, Blanco P, Nigrovic PA (2012) Platelets: active players in the pathogenesis of arthritis and SLE. Nat Rev Rheumatol 8:534-542

67. Senzel L, Gnatenko DV, Bahou WF (2009) The platelet proteome. Curr Opin Hematol 16(5):329-333

68. Cloutier N, Tan S, Boudreau LH, Cramb C, Subbaiah R, Lahey L, Albert A, Shnayder R, Gobezie R, Nigrovic PA et al (2013) The exposure of autoantigens by microparticles underlies the formation of potent inflammatory components: the microparticle-associated immune complexes. EMBO Mol Med 5:235-249

69. Cloutier N, Pare A, Farndale RW, Schumacher HR, Nigrovic PA, Lacroix S et al (2012) Platelets can enhance vascular permeability. J Am Soc Hematol 120:1334-1343

70. Gitz E, Pollitt AY, Gitz-Francois JJ, Alshehri O, Mori J, Montague S, Nash GB, Douglas MR, Gardiner EE, Andrews RK et al (2014) CLEC-2 expression is maintained on activated platelets and on platelet microparticles. Blood 124:2262

71. Pietraforte D, Vona R, Marchesi A, de Jacobis IT, Villani A, Del Principe D, Straface E (2014) Redox control of platelet functions in physiology and pathophysiology. Antioxid Redox Signal 21(1):177-193

72. Knijff-Dutmer EAJ, Koerts J, Nieuwland R, Kalsbeek-Batenburg EM, Van De Laar MAFJ (2002) Elevated levels of platelet microparticles are associated with disease activity in rheumatoid arthritis. Arthritis Rheum 46:1498-1503

73. Nurden AT (2011) Platelets, inflammation and tissue regeneration. Thromb Haemost 105(Suppl 1):S13-S33

74. Almasry SM, Soliman HM, El-Tarhouny SA, Algaidi SA, Ragab EM (2015) Platelet rich plasma enhances the immunohistochemical expression of platelet derived growth factor and vascular endothelial growth factor in the synovium of the meniscectomized rat models of osteoarthritis. Ann Anat 197:38-49

75. Vallés J, Santos MT, Aznar J, Martínez M, Moscardó A, Piñón M, Broekman MJ, Marcus AJ (2002) Platelet-erythrocyte interactions enhance $\alpha$ IIb $\beta 3$ integrin receptor activation and P-selectin expression during platelet recruitment: down-regulation by aspirin ex vivo. Blood 99(11):3978-3984

76. Valles J, Santos M, Aznar J, Marcus A, Martinez-Sales V, Portoles M, Broekman M, Safier L (1991) Erythrocytes metabolically enhance collagen-induced platelet responsiveness via increased thromboxane production, adenosine diphosphate release, and recruitment. Blood 78:154-162

77. Berckmans RJ, Nieuwland R, Tak PP, Böing AN, Romijn FP, Kraan MC, Breedveld FC, Hack CE, Sturk A (2002) Cellderived microparticles in synovial fluid from inflamed arthritic joints support coagulation exclusively via a factor VII-dependent mechanism. Arthritis Rheum 46(11):2857-2866

78. Danesh A, Inglis HC, Jackman RP, Wu S, Deng X, Muench MO, Heitman JW, Norris PJ (2014) Exosomes from red blood cell units bind to monocytes and induce proinflammatory cytokines, boosting T-cell responses in vitro. Blood 123:687-696

79. Biró É, Nieuwland R, Tak PP, Pronk LM, Schaap MC, Sturk A, Hack CE (2007) Activated complement components and complement activator molecules on the surface of cell-derived microparticles in patients with rheumatoid arthritis and healthy individuals. Ann Rheum Dis 66(8):1085-1092

80. Beyer C, Pisetsky DS (2010) The role of microparticles in the pathogenesis of rheumatic diseases. Nat Rev Rheumatol $6(1): 21-29$ 
81. Jy W, Johansen ME, Bidot C, Horstman LL, Ahn YS (2013) Red cell-derived microparticles (RMP) as haemostatic agent. Thromb Haemost 110(4):751-760

82. Horne MK, Cullinane AM, Merryman PK, Hoddeson EK (2006) The effect of red blood cells on thrombin generation. $\mathrm{Br}$ J Haematol 133(4):403-408

83. Whelihan MF, Mann KG (2013) The role of the red cell membrane in thrombin generation. Thromb Res 131(5):377-382

84. Bonomini M, Sirolli V, Merciaro G, Antidormi T, Di Liberato L, Brummer U, Papponetti M, Cappelli P, Di Gregorio P, Arduini A (2005) Red blood cells may contribute to hypercoagulability in uraemia via enhanced surface exposure of phosphatidylserine. Nephrol Dial Transplant 20(2):361-366

85. Spoerke NJ, Van PY, Differding JA, Zink KA, Cho SD, Muller PJ, Karahan ZA, Sondeen JL, Holcomb JB, Schreiber MA (2010) Red blood cells accelerate the onset of clot formation in polytrauma and hemorrhagic shock. J Trauma Acute Care Surg 69(5):1054-1061

86. Goldschmidt N, Spectre G, Brill A, Zelig O, Goldfarb A, Rachmilewitz E, Varon D (2008) Increased platelet adhesion under flow conditions is induced by both thalassemic platelets and red blood cells. Thromb Haemost 100(5):864-870

87. Perez V, Johansen ME, Jy W, Horstman L, Ahn YS (2013) Interaction of platelets with red cell-derived microparticles (RMP): RMP increase platelet aggregate size in a shear-dependent manner. Blood 122(21):3580

88. Xiong Z, Cavaretta J, Qu L, Stolz DB, Triulzi D, Lee JS (2011) Red blood cell microparticles show altered inflammatory chemokine binding and release ligand upon interaction with platelets. Transfusion 51(3):610-621

89. Hakala M, Risteli L, Manelius J, Nieminen P, Risteli J (1993) Increased type I collagen degradation correlates with disease severity in rheumatoid arthritis. Ann Rheum Dis 52(12):866-869

90. King KL, Cidlowski JA (1995) Cell cycle and apoptosis: common pathways to life and death. J Cell Biochem 58(2):175-180

91. Zwaal RFA, Comfurius P, Bevers EM (2005) Surface exposure of phosphatidylserine in pathological cells. CMLS, Cell Mol Life Sci 62(9):971-988
92. Abed M, Towhid ST, Mia S, Pakladok T, Alesutan I, Borst O, Gawaz M, Gulbins E, Lang F (2012) Sphingomyelinaseinduced adhesion of eryptotic erythrocytes to endothelial cells. Am J Physiol Cell Physiol 303(9):C991-C999

93. Walker B, Towhid ST, Schmid E, Hoffmann SM, Abed M, Münzer P, Vogel S, Neis F, Brucker S, Gawaz M et al (2014) Dynamic adhesion of eryptotic erythrocytes to immobilized platelets via platelet phosphatidylserine receptors. Am J Physiol Cell Physiol 306:C291-C297

94. Hermand P, Gane P, Huet M, Jallu V, Kaplan C, Sonneborn HH, Cartron J-P, Bailly P (2003) Red cell ICAM-4 is a novel ligand for platelet-activated $\alpha \operatorname{IIb} \beta 3$ integrin. J Biol Chem 278(7):4892-4898

95. Du VX, Huskens D, Maas C, Al Dieri R, de Groot PG, de Laat B (2014) New insights into the role of erythrocytes in thrombus formation. Semin Thromb Hemost 40(1):72-80

96. Hernández-Hernández A, Rodríguez MC, López-Revuelta A, Sánchez-Gallego JI, Shnyrov V, Llanillo M, Sánchez-Yagüe J (2006) Alterations in erythrocyte membrane protein composition in advanced non-small cell lung cancer. Blood Cells Mol Dis 36(3):355-363

97. Gupta P, Vijayan VK, Bansal SK (2012) Changes in protein profile of erythrocyte membrane in bronchial asthma. J Asthma 49(2):129-133

98. De Castro J, Hernández-Hernández A, Rodríguez MC, Sardina JL, Llanillo M, Sánchez-Yagüe J (2007) Comparison of changes in erythrocyte and platelet phospholipid and fatty acid composition and protein oxidation in chronic obstructive pulmonary disease and asthma. Platelets 18(1):43-51

99. Bochsen L, Johansson PI, Kristensen AT, Daugaard G, Ostrowski SR (2011) The influence of platelets, plasma and red blood cells on functional haemostatic assays. Blood Coagul Fibrinolysis 22(3):167-175

100. Santos M, Valles J, Lago A, Tembl J, Sanchez E, Moscardo A, Cosin J (2008) Residual platelet thromboxane A2 and prothrombotic effects of erythrocytes are important determinants of aspirin resistance in patients with vascular disease. $\mathrm{J}$ Thromb Haemost 6(4):615-621 